\title{
Efek Strategi Managerial Pada Kinerja Entitas Usaha Berskala Mikro
}

\author{
Ratna Septiyanti ${ }^{1}$ \\ Fakultas Ekonomi dan Bisnis \\ Universitas Lampung, Indonesia \\ Email: rseptiyanti@yahoo.com
}

\begin{abstract}
ABSTRAK
Penelitian ini menguji secara empiris pengaruh strategi manajerial terhadap kinerja entitas usaha berskala mikro di Indonesia. Sampel terdiri dari 2.527 entitas usaha berskala mikro di kota BandarLampung, Indonesia. Hasil penelitian menunjukkan bahwa strategi tipe tunggal memiliki efek negatif pada kinerja entitas berskala mikro. Strategi kemitraan memiliki efek positif pada kinerja entitas berskala mikro, baik dalam kemitraan keahlian maupun kemitraan finansial. Hasil empiris ini menunjukkan bahwa penerapan tata kelola yang baik pada entitas berskala mikro dapat meningkatkan kinerja. Penelitian ini memiliki implikasi praktis sebagai dasar teori empiris dalam merancang sistem pengukuran kinerja entitas berskala mikro. Entitas usaha berskala mikro harus dirancang dalam bentuk kemitraan keagenan untuk dapat meningkatkan kinerja. Implikasi kebijakan dari hasil penelitian ini berkaitan dengan dukungan regulasi perbankan bagi entitas usaha berskala mikro.
\end{abstract}

Kata Kunci: Sistem Pengukuran Kinerja; Tata Kelola yang Baik; Struktur; Strategi.

\section{Effects of Managerial Strategies on the Performance of Micro Scale Business Entities}

\section{ABSTRACT}

The research empirically examines the effect of managerial strategy on Indonesian micro entities' performance. The sample consists of 2,527 micro entities at Bandar Lampung city in Indonesia. The result shows that strategy of individually-managed has negative effect on micro entities' performance. The partnership strategy has a positive effect on its performance, both in enterpreneur and financial partnership. These empirical results indicate that the implementation of good governance on micro entities could increase its performance. The practical implication of this research is as an underlying empirical theory in designing performance measurement system for micro entities. Micro entities should be designed in an agency partnership form to increase its performance. The policy implication is due to a better lending regulation support.

Keywords: $\quad$ Performance Measurement System; Good Governance; Structure; Strategy.

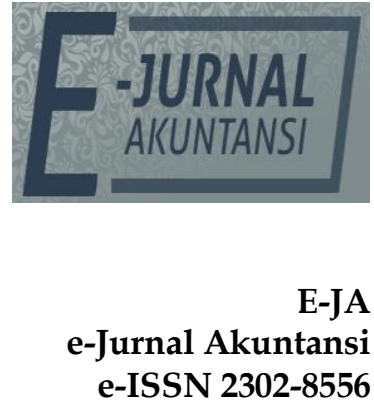

Vol. 30 No. 3

Denpasar, Maret 2020

Hal. 773-784

Artikel Masuk: 16 Desember 2019

Tanggal Diterima: 11 Maret 2020 


\section{PENDAHULUAN}

Fenomena usaha mikro, kecil, dan menengah (UMKM)sebagai tulang punggung dalam perekonomian suatu negara menarik untuk dikaji secara empiris. Berbagai penelitian menunjukkan bahwa UMKM memiliki peranan penting dalam pertumbuhan perekonomian negara, seperti dampak substansial sektor UMKM pada Gross Domestic Product (GDP) di Afrika Selatan (Kirsten, Vermaak, \& Wolmarans, 2015), efek sektor UMKM pada kinerja ekspor di Malaysia (Singh \& Mahmood, 2014), serta peran utama UMKM dalam perdagangan internasional di Inggris (Knight, 2001).

Kegiatan usaha bisnis pada sektor UMKM memiliki peranan strategis pula dalam perekonomi nasional di Indonesia. Porsi pelaku usaha bisnis, berdasarkan data Bank Indonesia tahun 2015, yang merupakan usaha bisnis UMKM adalah sebesar 99,99\% dari total keseluruhan pelaku usaha di Indonesia atau sebanyak 56,54 juta entitas usaha. LIPPI dan Bank Indonesia (2015) menguraikan data yang menunjukkan bahwa UMKM memberikan kontribusi terhadap Produk Domestik Bruto (PDB) sebesar 60\% dari total PDB di Indonesia. Produk Domestik Bruto merupakan jumlah nilai tambah yang dihasilkan oleh seluruh unit usaha dalam suatu negara tertentu, atau merupakan jumlah nilai barang dan jasa akhir yang dihasilkan oleh seluruh unit ekonomi. Adapun rincian kontribusi UMKM terhadap PDB Nasional menurut harga berlaku sebesar Rp4.869,5 triliun ataau 59,08\%. Total kontribusi UMKM terhadap PDB Nasional ini merupakan akumulasi dari semua sektor ekonomi UMKM yang ada di Indonesia. Hal ini mengindikasikan bahwa kondisi kinerja UMKM dapat memberikan dampak yang sangat besar dalam pertumbuhan perekonomian di Indonesia. Fenomena ini menjadi motivasi dalam penelitian ini untuk mengembangkan suatu model strategik peningkatan kinerja UMKM.

LIPPI dan Bank Indonesia (2015) menguraikan bahwa Kementrian Koperasi dan UMKM menjelaskan proporsi UMKM pada tahun 2014 adalah sebesar 59,08\% dari total entitas usaha yang ada di Indonesia, dengan rincian sebagai berikut: entitas usaha skala mikro sebesar $38,81 \%$, entitas usaha skala kecil sebesar 9,68\%, dan entitas usaha skala menengah sebesar 10,59\%. Hal ini menunjukkan bahwa entitas usaha berskala mikro memiliki porsi terbesar dalam sektor UMKM. Oleh karena itu, peningkatan kinerja UMKM harus difokuskan pada entitas berskala mikro.

Raselawati, (2011) menjelaskan bahwa UMKM berperan dalam mendorong percepatan pertumbuhan perekonomian melalui kegiatan ekspor dan penyerapan tenaga kerja sebanyak 70\% dari total tenaga kerja di Indonesia. Hapsari, Paramita, Hakim, \& Soeaidy (2014) menemukan bahwa faktor modal dan laba UMKM berpengaruh langsung dan signifikan secara statistik terhadap pertumbuhan perekonomian. Peran strategis UMKM dalam perekonomian nasional ini harus didukung dengan pengelolaanusahasecara professional agar dapat memberikan kinerja yang optimal.

Profesionalitas dalam pengelolaan entitas usaha bisnis sangat menentukan keberhasilan pencapaian kinerja yang optimal. Entitas usaha bisnis yang dijalankan dengan berlandaskan pada prinsip good governance dapat menghasilkan kinerja yang lebih baik. Todorovic (2013) menemukan bahwa perusahaan yang mengaplikasikan prinsip good corporate governance secara tepat 
cenderung mampu untuk meningkatkan profitabilitas, kemampuan kompetitif, kredibilitas, reputasi,dan memperbaiki hubungan dengan stakeholders, seperti investor, rekan bisnis, karyawan, dan para pelanggan. Bukti empiris ini menunjukkan bahwa corporate governance memiliki pengaruh positif terhadap kinerja perusahaan berskala besar.

Perbedaan penerapan corporate governance antara perusahaan berskala besar dengan entitas UMKM, dikarenakan entitas UMKM memiliki karakteristik unikyang berbeda dengan perusahaan berskala besar. Afrifa \& Tauringana (2015) menjelaskan bahwa perbedaan corporate governance perusahaan besar dengan UMKM di Inggris diakibatkan oleh struktur kepemilikan entitas UMKM yang tidak dapat melindungi kepentingan pemegang saham dari kekeliruan pengelolaan. Bridge, O'Neill, \& Cromie (1998) menjelaskan bahwa UMKM memiliki struktur kepemilikan yang unik yaitu pemilik memegang peran utama dalam mengelola dan mengendalikan usaha bisnis. Kondisi ini didukung oleh (Roida, Sunarjanto, \& Jayaprana, 2010) yang melakukan penelitian terhadap 315 sampel dari total populasi 2.910 UMKM yang berada di Jawa Timur, dan menemukan bahwa struktur kepemilikan UMKM di Jawa Timur seluruhnya dimiliki oleh keluarga. Garengo, Biazzo, \& Bititci, 2005 menemukan bahwa perbedaan sikap dan kapabilitas pemilik berpengaruh secara langsung pada organisasi. Selain itu, UMKM juga memiliki keterbatasan dalam sumberdaya dan modal Doole, Grimes, \& Demack (2006); Doern (2009). Berbagai bukti empiris tersebut mengindikasikan bahwa kondisi governance di sektor UMKM masih sangat lemah. Karakteristik yang melekat pada sektor UMKM ini cenderung akan menghasilkan kinerja yang terbatas. Oleh karena itu, perlu adanya suatu strategi manajerial berbasis good governance dalam upaya peningkatan kinerja UMKM, khususnya pada entitas usaha berskala mikro. Penelitian ini bertujuan untuk memberikan bukti empiris mengenai pengaruh strategi manajerial pada kinerja entitas usaha berskala mikro.

Penelitian ini dilandasi oleh teori keagenan (agency theory). Jensen \& Meckling (1976) menjelaskan bahwa perusahaan merupakan sekumpulan kontrak antar berbagai pihak yang terkait dengan kegiatan usahanya. Hubungan keagenan antara prinsipal dan agen menimbulkan adanya masalah keagenan. Konsekuensi dari adanya hubungan keagenan ini, menurut Jensen \& Meckling (1976) adanya biaya keagenan dalam mengatasi masalah keagenan, meskipun hubungan keagenan tersebut tidak jelas batasannya.

Fama \& Jensen (1983) memperluas teori keagenan bagi pengelolaan usaha bisnis sederhana berbentuk kerjasama profesi (partnership), kerjasama finansial (financial mutual), dan entitas nonprofit. Fama \& Jensen (1983) berargumen bahwa pengelolaan kerjasama bisnis sederhana seharusnya dilakukan dengan didasarkan pada adanya pemisahan antara kepemilikan dan pengelolaan usaha. Pemisahan kepemilikan dan pengelolaan ini harus dilandasi dengan adanya kontrak kerjasama, sehingga dapat menjaga kelangsungan dari kerjasama usaha bisnis yang sedang dijalankan. Entitas berskala mikro umumnya masih menjalankan usaha bisnis secara sederhana.

Pengelolaan entitas berskala mikro dari perspektif struktur governance inibersifat strategis bagi peningkatan kinerja entitas. Kerjasama keagenan (agency partnership) dalam bentuk kemitraan akan mendorong adanya pemonitoran dan 
pengendalian yang efektif dari pihak eksternal, sehingga pengelolaan entitas berskala mikro akan menjadi semakin baik. Pengelolaan entitas berskala mikro dengan berbasis pada good governance ini akan mendorong peningkatan kinerja. Hal ini berarti bahwa strategi manajerial berbasis kemitraan dapat memberikan kontribusi dalam pengukuran kinerja entitas berskala mikro.Model strategik peningkatan kinerja dalam penelitian ini berlandaskan pada perspektif strategi dan struktur dalam sistem pengukuran kinerja.

Implementasi strategi dan struktur dalam disain oganisasi telah dikembangkan oleh Chandler sejak tahun 1960-an dengan argumen structure follows strategy. Chandler $(1962,1966)$ menjelaskan bahwa struktur organisasi seharusnya didisain berdasarkan pada implementasi strategi organisasi dalam menghadapi kondisi ketidakpastian bisnis. Hall \& Saas (1980) menyatakan bahwa strategy follows structure dengan penjelasan alternatif dari sudut pandang alamiah bahwa strategi, struktur, dan lingkungan saling berkaitan. Hammond (1994) berargumen bahwa strategy follows structure, dengan penjelasan yang menggunakan teori agenda untuk menunjukkan bahwa keputusan strategi organisasi akan berbeda tergantung pada disain struktur organisasi. Habib \& Victor (1991) berargumen bahwa implementasi strategi memerlukan kesesuaian (fit) antara strategi dan struktur dalam peningkatan kinerja organisasi. Miller (1986) mengembangkan pendekatan konfigurasi sintesis antara strategi dan struktur.

Arosa, Iturralde, \& Maseda (2010) melakukan pengujian terhadap perusahaan-perusahaan kecil non-listed di Spanyol dan menemukan bahwa struktur kepemilikan keluarga memiliki pengaruh positif yang signifikan secara statistik terhadap kinerja. Werner, Schruder, \& Chlosta (2017) melakukan pengujian empiris mengenai struktur kepemilikan keluarga dan non-keluarga pada UMKM di Jerman Utara. Werner, Schruder, \& Chlosta (2017) menemukan bahwa UMKM di Jerman yang memiliki keterlibatan keluarga dalam kegiatan bisnisnya lebih inovatif dibandingkan dengan UMKM Jerman yang nonkeluarga. Generasi pertama pada perusahaan keluarga yang merupakan generasi pendiri usaha (founder generation) lebih inovatif dibandingkan perusahaan nonkeluarga, sedangkan generasi kedua pada perusahaan keluarga menghasilkan inovasi yang tidak berbeda dengan perusahan non-keluarga. Bukti empiris ini mengindikasikan bahwa pemilik awal yang mendirikan dan mengelola usaha bisnis keluarga lebih memperhatikan kualitas bisnisnya dibandingkan pemilik penerus yang mengelola usaha bisnis yang sudah berkembang dengan baik. Hasil penelitian Werner, Schruder, \& Chlosta (2017) ini menunjukkan bahwa usaha keluarga pada entitas berskala kecil memberikan pengaruh positif terhadap kualitas hasil usaha.

Afrifa \& Tauringana (2015) melakukan pengujian terhadap 234 UMKM yang terdaftar di Alternative Investment Market (AIM) di Inggris periode 20042013 dan menemukan bahwa struktur corporate governance berpengaruh pada kinerja UMKM di Inggris. Meijaard, Brand, \& Mosselman (2005) melakukan pengujian mengenai hubungan antara struktur organisasi dan kinerja perusahaan dengan menggunakan sampel berjumlah 1,411 perusahaan kecil di Belanda. Hasil penelitian Meijaard, Brand \& Mosselman (2005) memberikan bukti empiris bahwa struktur organisasi merupakan faktor penting dalam 
peningkatan kinerja perusahaan kecil. Perusahaan kecil harus membangun struktur organisasi yang memadai apabila perusahaan kecil tersebut memiliki hubungan keagenan.

Strategi memiliki hubungan positif, dan kuat secara empiris, terhadap kinerja. Singh \& Mahmood (2014) memberikan bukti empiris bahwa ada pengaruh positif yang signifikan antara strategi dan kinerja perusahaan berskala kecil dan medium di Malaysia. Yuliansyah, Gurd, \& Mohamed (2017) menguji pengaruh strategi bisnis terhadap kinerja institusi finansial di Indonesia dan menemukan bahwa strategi bisnis berpengaruh terhadap kinerja. $\mathrm{R} \mathrm{H}$ Chenhall \& Langfield-Smith (2007) mengembangkan pengukuran kinerja dengan menggunakan perspektif ganda yang berfokus tidak hanya pada ukuran finansial, tetapi juga mempertimbangkan ukuran non-finansial. Yuliansyah \& Khan (2015) yang menggunakan fokus strategi dalam sistem pengukuran kinerja secara interaktif.

Model strategik peningkatan kinerja dalam penelitian ini dikembangkan dari perspektif pengelolaan entitas berskala mikro berbasis kerjasama keagenan (agency partnership). Strategi manajerial entitas berskala mikro dalam penelitian ini dikategorikan menjadi dua tipe, yaitu: (1) tipe struktur tunggal, dimana pengelolaan entitas berskala mikrodilakukan secara individual oleh pemilik entitas, dan (2) tipe struktur kemitraan (agency partnership). Adapun strategi tipe kemitraan dikelompokkan menjadi dua, yaitu: (a) tipe kemitraan berdasarkan kerjasama keahlian (enterpreneurpartnership), dan (b) tipe kemitraan berdasarkan kontribusi finansial dalam struktur permodalan UMKM (financial partnership).

Usaha bisnis entitas UMKM di Indonesia umumnya terkendala sumberdaya finansial dan sumberdaya manusia. Sudiarta, Kirya, \& Cipta (2014) melakukan penelitian mengenai UMKM di Kabupaten Bangli dan memberikan bukti empiris bahwa kinerja UMKM lebih dominan dipengaruhi oleh faktor internal berupa sumber daya manusia dan finansial. Keterbatasan sumberdaya ini menyebabkan pelaku bisnis berskala mikro lebih cenderung untuk menjalankan sendiri usaha bisnisnya. Kondisi ini membatasi penerapan good governance dalam pengelolaan bisnis entitas berskala mikro.

Jensen \& Meckling (1976) menjelaskan perilaku agen yang memiliki perusahaan secara penuh atau agen yang memiliki seratus persen residual claims atas perusahaan akan mengambil keputusan operasional yang memaksimalkan utilitas pribadi yang akan menghasilkan benefit dari berbagai aspek yang berasal dari aktivitas bisnis (enterpreneurial activities) yang dilakukannya tersebut. Hal ini mengindikasikan bahwa model governance tipe tunggal yang digunakan sebagai strategi pengelolaan pada entitas usaha berskala mikro cenderung memberikan efek negatif pada kinerja, karena tidak ada pemonitoran dan pengendalian dari pihak eksternal. Oleh karena itu, hipotesis pertama dalam penelitian ini dapat dirumuskan seperti pada $\mathrm{H}_{1}$.

$\mathrm{H}_{1}$ : Strategi manajerial tipe tunggal berpengaruh negatif terhadap kinerja entitas berskala mikro.

Pengelolaan UMKM dengan menggunakan strategi tipe kerjasama kemitraan (agency partnership) menimbulkan adanya aspek pemonitoran dan pengendalian (controlling) dari pihak eksternal. Sudiarta, Kirya, \& Cipta (2014) memberikan bukti empiris bahwa kinerja UMKM lebih dominan dipengaruhi 
oleh faktor internal, diantaranya berupa sumber daya manusia. Oleh karena itu, model governance tipe kemitraan keahlian sangat dibutuhkan untuk dapat meningkatkan kinerja entitas berkala mikro. Strategi pengelolaan tipe kemitraan keahlian (enterpreneurpartnership) memberikan nuansa pemonitoran antar agen, yang memiliki keahlian (skill) berbeda,dalam pengelolaan entitas berskala mikro, sehingga dapat menciptakan pengendalian kegiatan operasional bisnis yang lebih baik. Semakin beragam tingkat keahlian yang dimiliki agen dalam tim manajemen akan memberikan efek pemonitoran dan pengendalian yang semakin baik dalam pengelolaan entitas usaha berskala mikro.Kondisi pemonitoran dan pengendalian yang baik ini cenderung dapat menghasilkankinerja yang baik. Hal ini mengindikasikan bahwa strategi manajerialtipe kemitraan keahlian (enterpreneur partnership) dapat memberikan efek positif terhadap kinerja entitas usaha berskala mikro. Oleh karena itu, hipotesis kedua dalam penelitian ini dirumuskan seperti pada $\mathrm{H}_{2}$.

$\mathrm{H}_{2}$ : Strategi manajerial tipe kemitraan keahlian berpengaruh positif terhadap kinerja entitas berskala mikro.

Keterbatasan modal merupakan kendala bagi entitas berskala mikro untuk dapat menghasilkan kinerja yang baik bagi kelangsungan hidup usaha bisnis yang dijalani. Sudiarta, Kirya, \& Cipta (2014) memberikan bukti empiris bahwa kinerja UMKM lebih dominan dipengaruhi oleh faktor internal, diantaranya berupa sumber daya modal. Kerjasama keagenan (agency partnership) di bidang finansial dapat memperbaiki kondisi finansial entitas berskala mikro, sehingga dapat mendorong entitas berskala mikro untuk menghasilkan kinerja yang baik.

Konsekuensi dari kemitraan finansial ini adalah adanya pemonitoran danpengendalian (controlling) dari pihak eksternal. Kondisi ini akan mengakibatkan pengelolaan entitas entitas berskala mikro menjadiyang lebih baik, sehingga dapat meningkatkan kinerja. Hal ini berarti bahwa pengelolaan entitas berskala mikro dengan menggunakan strategi manajerial tipe kemitraan finansial (financial partnership) dapat memberikan efek positif pada kinerja entitas berskala mikro. Oleh karena itu, hipotesis ketiga dalam penelitian ini dirumuskan seperti pada $\mathrm{H}_{3}$.

$\mathrm{H}_{3}$ : Strategi manajerial tipe kemitraan finansial berpengaruh positif terhadap kinerja entitas berskala mikro.

Rerangka konseptual penelitian yang diuraikan dalam pengembangan hipotesis yang akan diuji dalam penelitian ini dapat dilihat pada Gambar 1 . berikut.

$$
\begin{aligned}
& X \\
& \text { Strategi Managerial } \\
& X_{1}=\text { Tipe Tunggal } \\
& \mathrm{X}_{2}=\text { Tine Kemitraan Keahlian } \\
& \mathrm{X}_{2}=\mathrm{T} \text {. }
\end{aligned}
$$

Sumber: Rangka Konseptual, 2019

\section{Gambar 1. Rangka Konseptual}




\section{METODE PENELITIAN}

Populasi yang digunakan dalam penelitian ini merupakan seluruh entitas UMKM yang ada di Bandarlampung. Metoda pengumpulan data menggunakan field survey, untuk mendapatkan data-data pengelolaan dan keuangan secara langsung dari narasumber. Metoda ini digunakankarena belum ada database yang memiliki informasi memadai mengenai UMKM. Pemilihan sampel dilakukan berdasarkan sampling frame berupaentitas usaha berskala mikroyang terdaftar pada Dinas Koperasi, Usaha Kecil dan Menengah, Perindustrian dan Perdagangan Kota Bandarlampung. Oleh karena itu, pada saat pengumpulan data di lapangan, entitas yang ada namun tidak terdaftar pada database Pemerintah Daerah maka tidak digunakan sebagai sampel penelitian. Pembatasan pemilihan sampel ini dilakukan untuk memastikan bahwa kondisi kinerja entitas usaha berskala mikroyang dijadikan sampel penelitian ini terukur dalam perekonomian Indonesia.

Tabel 1. menjelaskan proses pemilihan sampel. Populasi entitas Usaha Mikro, Kecil, dan Menengah (UMKM) yang terdaftar pada Pemerintah Daerah sebanyak 6.261 UMKM. Entitas usaha berskala mikro yang ada di lapangan sebanyak 2.532 yang tersebar di 20 kecamatan yang ada di Kota Bandarlampung. Ada 5 entitas usaha berskala mikro yang dikeluarkan dari sampel karena data yang diperoleh tidak lengkap. Dengan demikian, total sampel yang dapat digunakan untuk pengujian hipotesis sebanyak 2.527 entitas.

\section{Tabel 1. Pemilihan Sampel}

\begin{tabular}{ll}
\hline Populasi pada database Dinas UMKM kota Bandarlampung & 6.261 \\
Entitas berskala Mikro yang ada di lapangan & 2.532 \\
Data tidak lengkap & 5 \\
Total Sampel & 2.527 \\
\hline
\end{tabular}

Sumber: Data Penelitian, 2019

Variabel dependen (Y) adalah kinerja entitas usaha, yang dioperasionalisasi sebagaijumlah pendapatan yang diperoleh oleh masingmasing entitas usaha berskala mikro. Variabel ini diukur dengan logaritma natural (ln) dari total pendapatan tahunan.

Variabel Independen $(\mathrm{X})$ yang digunakan dalam penelitian ini ada 3, yaitu: Variabel $X_{1}$ merupakan strategi managerial tipe tunggal. Variabel ini diukur dengan dummy variable, yaitu $\mathrm{X}_{1}=1$ jika entitas usaha berskala mikro dikelola secara individual, dan $X_{1}=0$ jika tidak dikelola secara individual. Variabel $\mathrm{X}_{2}$ merupakan strategi managerial tipe kemitraan keahlian. Variabel ini diukur dengan jumlah agen yang memiliki keahlian berbeda dalam tim manajemen entitas usaha berskala mikro. Variabel $X_{3}$ Strategi managerial tipe kemitraan finansial. Variabel ini diproksikan berdasarkan jumlah kontribusi finansial dalam struktur permodalanentitas usaha berskala mikro.

Pengujian hipotesis dalam penelitian ini dilakukan dengan menggunakan alat analisis berupa metode regresi Ordinary Least Square (OLS) berdasarkan model persamaan berikut:

$$
Y=\alpha+\beta_{1} X_{1}+\beta_{2} X_{2}+\beta_{3} X_{3}+\varepsilon .
$$

Keterangan:

$\mathrm{Y}=$ Kinerja

$\mathrm{X}_{1}=$ Strategi managerial tipe tunggal 
$\mathrm{X}_{2}=$ Strategi managerial tipe kemitraan keahlian

$\mathrm{X}_{3}=$ Strategi managerial tipe kemitraan finansial

$\alpha=$ Konstanta

$\beta=$ Koefisien regresi

$\varepsilon=$ Residual

HASIL DAN PEMBAHASAN

Tabel 2. Statistik Deskriptif

\begin{tabular}{llllll}
\hline & $\mathrm{N}$ & Min & Max & Mean & Std. Deviation \\
\hline $\mathrm{Y}$ & 2,527 & 8.00 & 20.00 & 15.64 & 1.25 \\
$\mathrm{X}_{1}$ & 2,527 & 0 & 1 & .66 & .48 \\
$\mathrm{X}_{2}$ & 2,527 & 1 & 7 & .76 & 1.10 \\
$\mathrm{X}_{3}$ & 2,527 & 0 & 5 & .49 & 1.12 \\
\hline
\end{tabular}

Sumber: Data Penelitian, 2019

Tabel 2. menampilkan Statistik Deskriptif. Variabel kinerja disimbolkan dengan Y. Entitas usaha berskala mikro memiliki pendapatan tahunan minimal sebesar 8 juta rupiah dan maksimal sebesar 20 juta rupiah, dengan nilai pendapatan rata-rata tahunan sebesar 15,64 juta rupiah.Variabel strategi tipe tunggal disimbolkan dengan $X_{1}$. Nilai mean entitas usaha berskala mikro yang menggunakan strategi tipe tunggal sebesar 0,66 dari total sampel. Variabel strategi tipe kemitraan keahlian disimbolkan dengan $\mathrm{X}_{2}$. Strategi tipe kemitraan keahlian memiliki nilai minimal 1 yang berarti bahwa entitas usaha dikelola secara individual dan nilai maksimal 7 yang berarti bahwa ada entitas usaha yang menggunakan strategi kemitraan keahlian dengan keragaman sebanyak 7 jeniskeahlian dalam mengelola entitas usaha. Adapun, nilai mean untuk tipe strategi kemitraan keahlian sebesar 0,76. Variabel strategi tipe kemitraan finansial disimbolkan dengan $X_{3}$. Strategi tipe kemitraan finansial memiliki nilai minimal nol yang berarti entitas usaha tidak memiliki kemitraan finansial, atau dengan kata lain entitas usaha dijalankan dengan menggunakan modal sendiri. Nilai maksimal variabel kemitraan finansial sebesar 5 yang berarti entitas usaha memiliki paling banyak 5 sumber yang berkontribusi dalam bahwa struktur permodalan.

Hasil pengujian hipotesisdapat dilihat dalam Tabel 3. Hasil pengujian model yang digunakan dalam pengujian hipotesis ini dapat dikategorikan sebagai model yang baik. Nilai F statistik sebesar 297,971 dengan nilai signifikansi sebesar 0,000. Nilai $R$-square sebesar 0,262 menunjukkan bahwa model penelitian ini dapat menjelaskan pola hubungan antar variabel dependen dan independen sebesar 26,2\%. Pola hubungan ini konsisten dengan nilai adjusted $R$-square sebesar 0,261 . 
Tabel 3. Hasil Regresi

$$
Y=\alpha+\beta_{1} X_{1}+\beta_{2} X_{2}+\beta_{3} X_{3}+\varepsilon
$$

\begin{tabular}{|c|c|c|c|c|c|c|c|c|}
\hline & $\begin{array}{l}\text { a } \\
\text { (Sig.) }\end{array}$ & $\begin{array}{l}\beta_{1} \\
\text { (Sig.) }\end{array}$ & $\begin{array}{l}\beta_{2} \\
\text { (Sig.) }\end{array}$ & $\begin{array}{l}\beta_{3} \\
\text { (Sig.) }\end{array}$ & $\mathrm{R}^{2}$ & $\begin{array}{l}\text { Adj. } \\
R^{2}\end{array}$ & $\begin{array}{l}\text { F } \\
\text { (Sig.) }\end{array}$ & $\mathrm{N}$ \\
\hline $\begin{array}{l}\text { Model- } \\
\text { Mikro }\end{array}$ & $\begin{array}{l}15.458 \\
(.000)^{* *}\end{array}$ & $\begin{array}{l}-.292 \\
(.039)^{*}\end{array}$ & $\begin{array}{l}.246 \\
(.000)^{* *}\end{array}$ & $\begin{array}{l}.053 \\
(.000)^{* *}\end{array}$ & .262 & 261 & $\begin{array}{l}297.971 \\
(.000)^{* *}\end{array}$ & 2,527 \\
\hline \multirow{2}{*}{\multicolumn{9}{|c|}{$\begin{array}{l}\mathrm{Y}=\text { Kinerja } \\
\mathrm{X}_{1}=\text { Strategi manajerial tipe tunggal }\end{array}$}} \\
\hline & & & & & & & & \\
\hline \multicolumn{9}{|c|}{$\mathrm{X}_{2}=$ Strategi manajerial tipe kemitraan keahlian } \\
\hline \multirow{2}{*}{\multicolumn{9}{|c|}{$\mathrm{X}_{3}=$ Strategi manajerial tipe kemitraan finansial }} \\
\hline & \multicolumn{8}{|c|}{$* *$ : significant at $1 \%$} \\
\hline * : sign & ht at $5 \%$ & & & & & & & \\
\hline
\end{tabular}

\section{Sumber: Data Penelitian, 2019}

Tabel 3. menunjukkan hasil pengujian secara statistik menggunakan model regresi. Nilai koefisien regresi $\beta_{1}$ sebesar -0,292 dengan nilai signifikansi sebesar 0,039. Hasil ini menunjukkan bahwa variabel $X_{1}$ berupa strategi managerial tipe tunggal memiliki pengaruh negatifyang signifikan secara statistik terhadap kinerja. Hasil pengujian ini menunjukkan bahwa hipotesis 1 didukung.

Nilai koefisien regresi $\beta_{2}$ sebesar 0,246 dengan nilai signifikansi sebesar 0,000 . Hasil ini menunjukkan bahwa variabel $X_{2}$ berupa strategi managerial tipe kemitraan keahlian memiliki pengaruh yang positif dan signifikan secara statistik terhadap kinerja. Hasil pengujian ini menunjukkan bahwa hipotesis 2 didukung.

Nilai koefisien regresi $\beta_{3}$ sebesar 0,053 dengan nilai signifikansi sebesar 0,000 . Hasil ini menunjukkan bahwa variabel $X_{3}$ berupa strategi managerial tipekemitraan finansial memiliki pengaruh yang positif dan signifikan secara statistik terhadap variabel kinerja. Hasil pengujian ini menunjukkan bahwa hipotesis 3 didukung.

Hasil penelitian ini memberikan bukti empiris bahwa kinerja entitas usaha berskala mikro sangat bergantung pada tipe strategi managerial yang digunakan dalam pengelolaan usaha bisnis. Pemilihan strategi managerial secara tepat dalam model pengelolaan bisnis pada entitas usaha berskala mikro, maka akan menghasilkan kinerja yang semakin baik.Strategi managerial tipe tunggal akan memberikan efek negatif terhadap kinerja entitas usaha berskala mikro. Hasil penelitian ini menunjukkan bahwa strategi managerial yang tepat dalam model pengelolaan entitas usaha berskala mikro adalah menggunakan tipe kemitraan, baik kemitraan dalam bidang keahlian maupun kemitraan dalam bidang finansial. Strategi kemitraan ini akan memberikan efek positif pada kinerja entitas usaha berskala mikro.

Bukti empiris yang diperoleh dalam penelitian ini menunjukkan arti penting penggunaan strategi dan struktur yang berbasis good governance dalam meningkatkan kinerja entitas usaha berskala mikro.Hasil penelitian ini konsisten dan komplemen atau saling melengkapi dengan penelitian Todorovic (2013) dalam hal implementasi good corporate governance secara tepat pada perusahaan 
besar dapat meningkatkan kinerja.Hasil penelitian ini juga konsisten dengan temuan dari penelitian Yuliansyah, Gurd, \& Mohamed (2017) yang mendukung penggunaan strategi bisnis dalam meningkatkan kinerja organisasi, serta konsisten pula hasil penelitian (Yuliansyah \& Khan (2015) yang menggunakan fokus strategi dalam sistem pengukuran kinerja secara interaktif.

Hasil penelitian ini memperkaya teori keagenan, khususnya dalam pengaplikasian good governance pada sektor usaha berskala mikro, konsisten dengan Fama \& Jensen (1983). Hasil penelitian ini juga mendukung konsep strategi dan struktur yang dikembangkan oleh Chandler $(1962,1966)$ terutama untuk pengembangan disain strategi dan struktur pada sektor usaha berskala mikro.Penelitian ini juga memperkaya teori sistem pengukuran kinerja strategik (Robert H Chenhall, 2005; R H Chenhall \& Langfield-Smith, 1998, 2007) khususnya dalam bidang pengukuran kinerja entitas usaha berskala mikro.

\section{SIMPULAN}

Penelitian ini memberikan bukti empiris mengenai efek strategi manajerial pada kinerja entitas usaha berskala mikro. Strategi manajerial tipe tunggal memberikan efek negatif pada kinerja entitas usaha berskala mikro. Strategi manajerial berbasis kemitraan, baik kemitraan keahlian maupun kemitraan finansial, memberikan efek positif pada kinerja entitas usaha berskala mikro. Pemilihan strategi pengelolaan usaha bisnis secara tepat dapat menghasilkan kinerja yang baik. Oleh karena itu, pengelolaan entitas usaha berskala mikro harus dilandaskan pada good governance dalam bentuk pola kemitraan agar dapat meningkatkan kinerja. Peningkatan kinerja entitas usaha berskala mikro dapat mendorong pertumbuhan perekonomian nasional.

Implikasi pada tataran praktis, hasil penelitian ini dapat digunakan oleh para enterpreneur entitas usaha berskala mikro sebagai landasan dalam mengembangkan model peningkatan kinerja berbasis good governance dengan mendisain pola kerjasama keagenan dalam bentuk kemitraan keahlian dan kemitraan finansial. Implikasi sosial dari peningkatan kinerja entitas usaha berskala mikro ini adalah pada kontribusi agregasi sektor UMKM pada pertumbuhan perekonomian nasional secara keseluruhan. Adapun implikasi kebijakan penelitian ini adalah sebagai dasar dalam mendisain regulasi finansial di sektor perbankan untuk pengembangan sektor bisnis UMKM, khususnya bagi usaha berskala mikro di Indonesia.

\section{REFERENSI}

Afrifa, G., \& Tauringana, V. (2015). Corporate governance and performance of UK listed small and medium enterprises. In (Vol. 15, pp. 719-733): Corporate Governance.

Arosa, B., Iturralde, T., \& Maseda, A. (2010). Ownership structure and firm performance in non-listed firms: Evidence from Spain. In (Vol. 1, pp. 88-96): Journal of Family Business Strategy, Elsevier.

Bridge, S., O'Neill, K., \& Cromie. (1998). Understanding Enterprise, Entrepreneurship and small Business. In. London: Macmillan Business.

Chandler, A. D. (1962). Strategy and Structure: Chapters in the History of American Enterprise. In. Boston: MIT Press. 
Chandler, A. D. (1966). Strategy and Structure. In. New York: Doubleday, Anchor Books Edition.

Chenhall, R. H. (2005). Integrative strategic performance measurement systems, strategic alignment of manufacturing, learning and strategic outcomes: an exploratory study. In (Vol. 30, pp. 395-422): Accounting, Organizations and Society.

Chenhall, R. H., \& Langfield-Smith, K. (1998). The Relationship between Strategic Priorities, Management Techniques and ManagementAccounting: An Empirical Investigation Using a Systems Approach. In (Vol. 23, pp. 243-264): Accounting, Organizations and Society.

Chenhall, R. H., \& Langfield-Smith, K. (2007). Multiple Perspectives on Performance Measures. In (Vol. 25, pp. 266-282): European Management Journal.

Doern, R. (2009). Investigating Barriers to SME Growth and Development in Transition Environments: A Critique and Suggestions for Developing the Methodology. In (Vol. 27, pp. 275-305): International Small Business Journal.

Doole, I., Grimes, T., \& Demack, S. (2006). An Exploration of the Management Practices and Processes Most Closely Associated with High Levels of Export Capability in SMEs. In (Vol. 24, pp. 632-647): Marketing Intelligence and Planning.

Fama, E. F., \& Jensen, M. C. (1983). Separation of Ownership and Control. In (Vol. XXVI): Journal of Law and Economics.

Garengo, P., Biazzo, S., \& Bititci, U. S. (2005). Performance Measurement Systems in SMEs: A Review for a Research Agenda . In (Vol. 7, pp. 25-47): Journal of Management Reviews.

Habib, M. M., \& Victor, B. (1991). Strategy, Structure, and Performance of U.S. Manufacturing and Service MNCs: A Comparative Analysis. In (Vol. 12, pp. 589-606): Strategic Management Journal.

Hall, D. J., \& Saas, M. A. (1980). Strategy Follows Structure! In (Vol. 1, pp. 149163): Strategic Management Journal.

Hammond, T. H. (1994). Structure, Strategy, and the Agenda of the Firms . In R. P. Rumelt, Schendel, D. J. Teece, \& eds (Eds.), Fundamental Issues in Strategy: A Research Agenda. Boston: Harvard Business School Press.

Hapsari, Paramita, P., Hakim, A., \& Soeaidy, S. (2014). Pengaruh Pertumbuhan Usaha Kecil Menengah (UKM) terhadap Pertumbuhan Ekonomi Daerah (Studi di Pemerintah Kota Batu). In (Vol. 17): Wacana.

Indonesia, L. d. B. (2015). Profil Bisnis Usaha Mikro, Kecil, dan Menengah (UMKM). Kerjasama Lembaga Pengembangan Perbankan Indonesia tahun 2015

Jensen, M. C., \& Meckling, W. H. (1976). Theory of the Firm: Managerial Behavior, Agency Costs and Ownership Structure. In (Vol. 3, pp. 305360): Journal of Financial Economics.

Kirsten, Vermaak, \& Wolmarans. (2015). Performance Measurement in Small and Medium Enterprises: South African Accountants' View. In (Vol. 8, pp. 13-34): Journal of Economic and Financial Sciences. 
Knight, G. A. (2001). Entrepreneurship and Strategy in the International SME. In (Vol. 7, pp. 155-171): Journal of International Management.

Meijaard, J., Brand, J. M., \& Mosselman, M. (2005). Organizational Structure and Performance in Dutch Small Firms. In: Scientific Analysis if Enterpreneurship and SMEs (SCALES) Paper N200420. Business and Policy Research (EIM). The Netherlands' Ministry of Economic Affairs. www.eim.nl/smes-and-entrepreneurship .

Miller, D. (1986). Configuration of Strategy and Structure: Toward a Synthesis. In (Vol. 7, pp. 233-249): Strategic Management Journal.

Raselawati, A. (2011). Pengaruh Perkembangan Usaha Kecil Menengah Terhadap Pertumbuhan Ekonomi pada Sektor UKM di Indonesia. In. Jakarta: Thesis. Universitas Islam Negeri Syarif Hidayatullah.

Roida, H. Y., Sunarjanto, N. A., \& Jayaprana, W. (2010). Internasionalisasi Usaha Mikro, Kecil, dan Menengah(UMKM) Ditinjau dari Tipe Kepemilikan: Studi Empiris di Jawa Timur. In (Vol. 3, pp. 158-170): Jurnal Manajemen Teori dan Terapan.

Singh, H., \& Mahmood, R. (2014). Combined Effect of Competitive and Manufacturing Strategies on Export Performance of Small and Medium Enterprises in Malaysia. In (Vol. Volume 14 Issue 1 Version 1.0): Global Journal of Management and Business Research: An Administration and Management.

Sudiarta, I. P. L. E., Kirya, I. K., \& Cipta, I. W. (2014). Analisis Faktor-Faktor yang Mempengaruhi Kinerja Usaha Mikro Kecil dan Menengah (UMKM) di Kabupaten Bangli . In (Vol. 2): e-Journal Bisma Universitas Pendidikan Ganesha Jurusan Manajemen.

Todorovic, I. (2013). Impact of Corporate Governance on Performance of Companies. In (Vol. 9, pp. 47-53): Montenegrin Journal of Economics.

Werner, A., Schruder, C., \& Chlosta, S. (2017). Driving Factors of Innovation in Family and Non-family SMEs. In (Vol. 50, pp. 201-218): Springer Science+ Business Media New York. Small Bus Econ (2018).

Yuliansyah, Gurd, B., \& Mohamed, N. (2017). TheSignificant of Business Strategy in Improving Organizational Performance. In (Vol. 33, pp. 56-74): Humanomics.

Yuliansyah, \& Khan, A. (2015). Interactive Use of Performance Measurement Systems and Organization's Customers-focused Strategy: The Mediating Role of Organizational Learning . In (Vol. 13, pp. 219-229): Problem and Perspectives in Management. 